\title{
Nighttime Radio Wave Scintillation at Equatorial Stations in Indian and American Zones
}

\author{
R. G. Rastogl, P. V. Koparkar, and B. M. Pathan \\ Indian Institute of Geomagnetism, Colaba, Bombay 400 005, India
}

(Received January 26, 1989; Revised November 2, 1989)

This paper reports studies of VHF radio wave scintillations during the nighttime in the Indian zone and compares the results with the corresponding data from the American sector. The seasonal variation of scintillations in the Indian sector showed maxima during equinoxes, compared to a single maxima during the December solistices in the American sector. Indian stations showed a very large decrease in scintillation activity with decreasing solar activity, compared to a very low dependence of scintillations on solar activity in the American sector. The geomagnetic disturbances tend to reduce the occurrence of scintillations more significantly in the Indian than American sector.

\section{Introduction}

The observation of scintillations of extremely short wavelength radio waves (in the $\mathrm{GHz}$ frequency range) from geostationary satellites at an equatorial station (TAUR, 1973) has generated renewed interest in studies of equatorial radio wave scintillations. These studies are very important for understanding the basic mechanisms of the generation of ionospheric irregularities, as well as for planning suitable satellite-based communication systems (AARONS, 1982) and for developing satellite-based radar systems (SZUSZCZEWICZ et al., 1983). It has been shown through multifrequency scintillations observations and $50 \mathrm{MHz}$ backscatter observations that the scale sizes of the irregularities coexisting during the generation phase of equatorial ionospheric irregularities varies from kilometer to meter size (BASU et $a l .$, 1978). The analysis of the global morphology of ionospheric scintillations by AARONS (1982) describes mainly the results from American and African longitudes. A fairly good amount of work on equatorial radio wave scintillations has been reported in the literature for the American zone (RASTOGI, 1982a, b; BASU and BASU, 1985). During the Condor campaign, various ground-based as well as satellite-based and rocket-borne techniques were used to probe equatorial ionosphere simultaneously, to have better understanding of the various processes involved (BASU et al., 1986; KELLEY et al., 1986, etc.). For the Indian zone, during the ATS-6 period (1975-76) multifrequency scintillation studies have been done at Trivandrum (KRISHNA MOORTHY et al., 1979) and Ootacamund (RASTOGI et al., 1982). The period of observation was less than a year, and therefore many features of radio wave scintillations could not be evaluated. With this view, a network of equatorial radio wave scintillations recording stations was established by the Indian Institute of Geomagnetism to understand the daily, latitudinal and seasonal 
variation of equatorial radio wave scintillations.

\section{Experimental Details}

In the present paper, the results of VHF scintillations at $244 \mathrm{MHz}$ are reported for the station at Trivandrum $\left(8.5^{\circ} \mathrm{N} ; 76.9^{\circ} \mathrm{E}\right.$ geographic; dip $\left.0.5^{\circ} \mathrm{N}\right)$. As viewed from Trivandrum, the geostationary satellite FLEETSAT $\left(73^{\circ} \mathrm{E}\right)$ is at an elevation of $78^{\circ}$ with azimuth of $25^{\circ}$ west of south. The sub-ionospheric coordinates at the $400 \mathrm{~km}$ height are $\left(7.9^{\circ} \mathrm{N} ; 76.7^{\circ} \mathrm{E}\right)$. Thus, in practical terms, the satellite was almost directly overhead at this station. Amplitude scintillations have been recorded at Trivandrum since July 1985, on a continuous basis. A simple eleven-element YagiUda antenna and indigenously made VHF receiver and a single channel strip chart recorder have been used for recording the amplitude of the signal. The data used in the present analysis pertain to a period of four years (July 1985 to June 1989). Hourly scalings of scintillations exceeding peak-to-peak fluctuations of $1 \mathrm{~dB}$ make up the basic data for the present analysis. These results for Trivandrum are compared with the data on scintillations on $137 \mathrm{MHz}$ at Huancayo $\left(12.0^{\circ} \mathrm{S}, 75.0^{\circ} \mathrm{W}\right.$ geographic; dip $2.0^{\circ} \mathrm{N}$ ) an equatorial station in the American sector, for the period June 69-May 75. The data at Huancayo are available in terms of a scintillation index computed after WHITNEY et al. (1969). It may be mentioned that scintillations $\geq 1 \mathrm{~dB}$ correspond to $\mathrm{SI} \geq 10 \%$.

\section{Results}

At Trivandrum, the onset of scintillations is usually abrupt, reaching peak-topeak amplitude exceeding $10 \mathrm{~dB}$ within a few minutes. During the pre-midnight period, the fading rate is very high and decreases with the progress of time. In the post-midnight period, a comparatively low scintillation fading rate is observed. On certain occasions, the onset of scintillations is rather slow in the beginning, with a lower fading rate. After some time, as the peak-to-peak amplitude reaches saturation level, the fading rate also picks up, and later on intense scintillations are observed. A few sample records for one such event which occurred on 16 February 1989 are shown in Fig. 1.

\subsection{Daily variation of scintillations}

First of all we have shown in Fig. 2 the nocturnal variations in the percentage occurrence of scintillations $\geq 1 \mathrm{~dB}$ or $\mathrm{SI} \geq 10 \%$ at Trivandrum and Huancayo for the three seasons, E-months (March, April, September, October), J-months (May, June, July, August) and D-months (November, December, January, February) the data are divided into low and high sunspot years. The percentage occurrence of scintillations $\geq 1 \mathrm{~dB}$ at Trivandrum during low sunspot years were found to be maximum around 22:00 hrs in the E- and D-months, while during the J-months the percentage occurrence of scintillations increased slowly and reached a maximum around 01:00 hrs. The magnitude of peak occurrence was about $35 \%$ in E-, $28 \%$ in D- and $20 \%$ during J-months. During the high sunspot period, scintillations at Trivandrum increased significantly in magnitude and the peak occurred at 22:00 or 23:00 hrs. In the American sector, the scintillations were significantly stronger than 


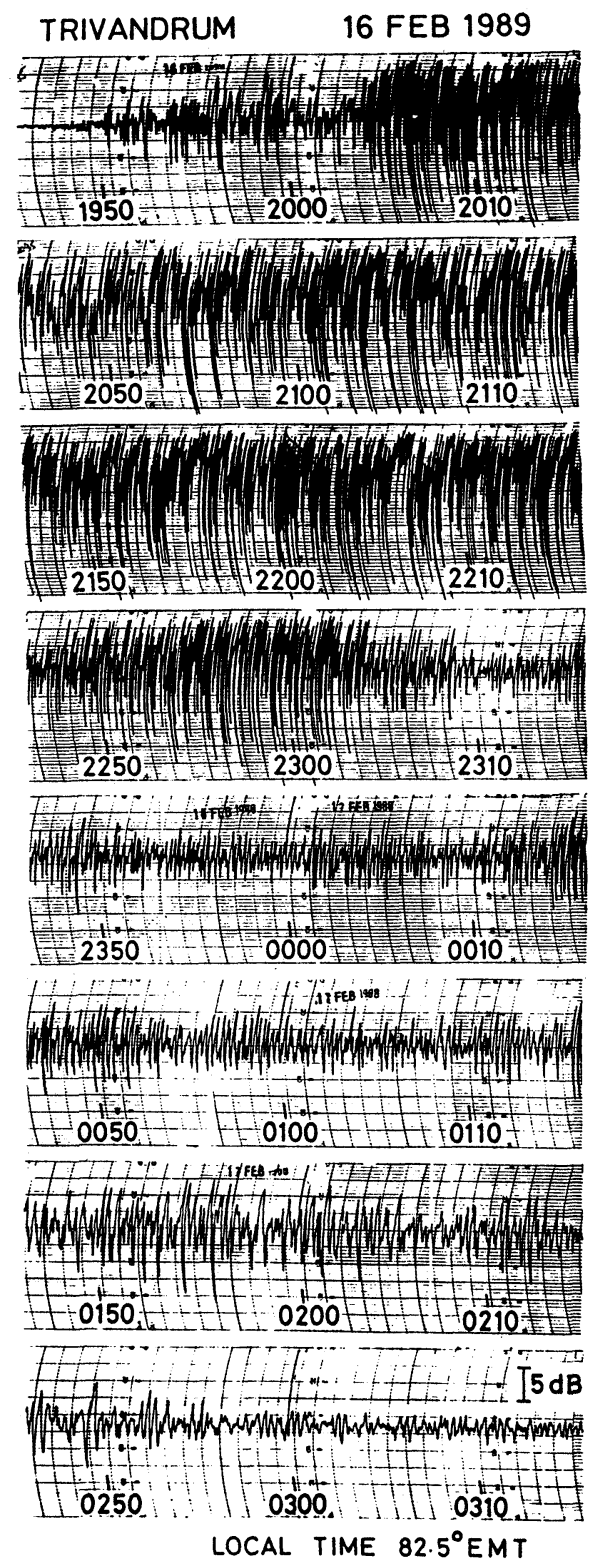

Fig. 1. Sample records of $244 \mathrm{MHz}$ scintillations recorded at Trivandrum on February 16, 1989.

in the Indian sector for either the low- or high-sunspot years. The magnitude of scintillations was largest during the D-months and least during the J-months. Thus, there seem to be very significant longitudinal differences in the equatorial scintillations in the Indian sector compared to those in the American sector. 


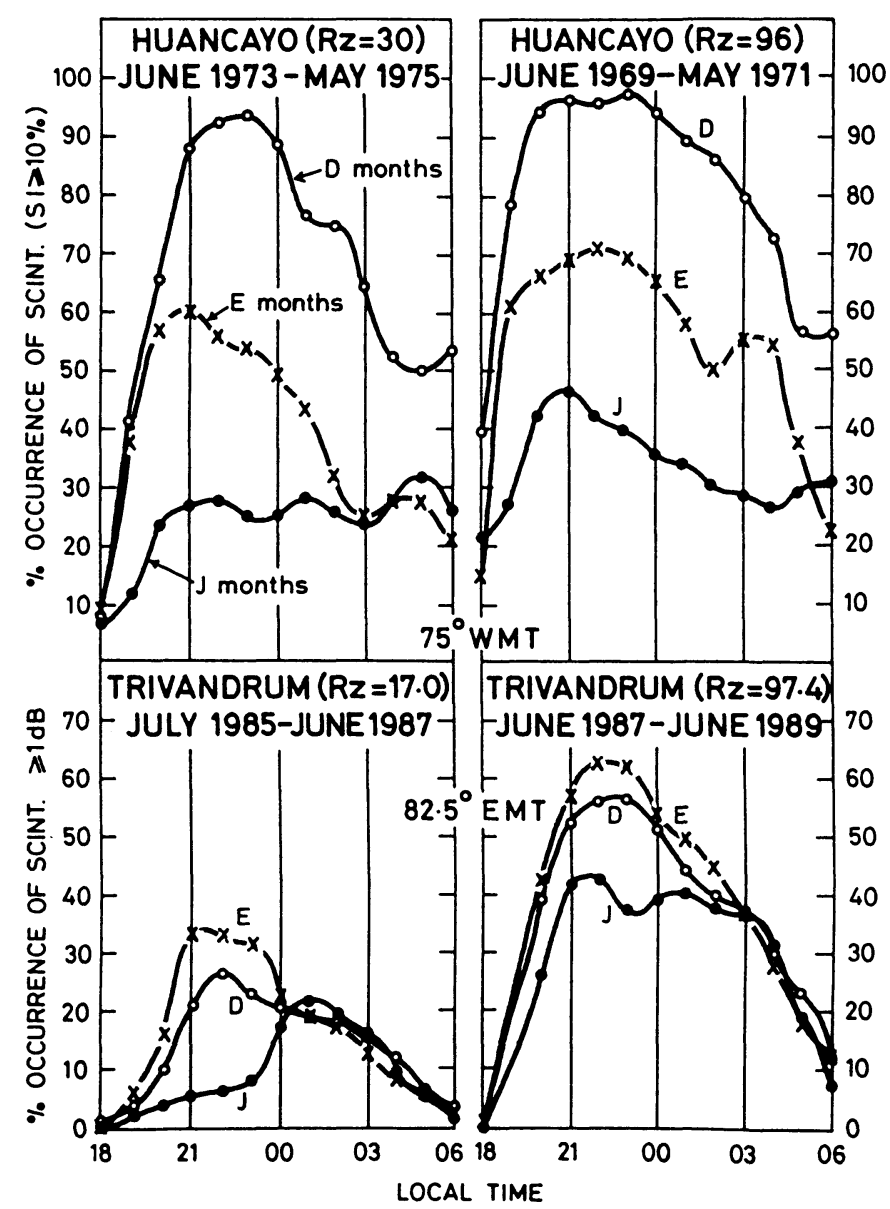

Fig. 2. Daily variations in the percentage occurrence of scintillations $\geq 1 \mathrm{~dB}$ at Trivandrum and $\mathrm{SI} \geq 10 \%$ at Huancayo for different seasons of low and high sunspot years.

\subsection{Seasonal variation of equatorial radiowave scintillations}

In order to understand the average temporal variation in scintillations in terms of time of day and season, in Fig. 3 we have drawn the contours of the isooccurrence of scintillations on the grid of local time and months for the years of low and high sunspots for Trivandrum and Huancayo. As discussed earlier (RASTOGI, 1982a, b) the peak scintillation at Huancayo occurs between December and January, with the minimum during June-July. During either the low or high sunspot years, the peak occurrence during the D-months is always more than $90 \%$, suggesting little effect of solar cycle changes. In contrast, scintillations at Trivandrum show predominantly equinoctial maxima during high as well as low sunspot years. There are secondary maxima in the post-midnight hours of low sunspot years. There is a significant increase of scintillations with solar activity.

In Fig. 4 we have plotted the monthly mean percentage occurrence of scintillations during the pre-midnight and post-midnight periods. As is clearly seen, 

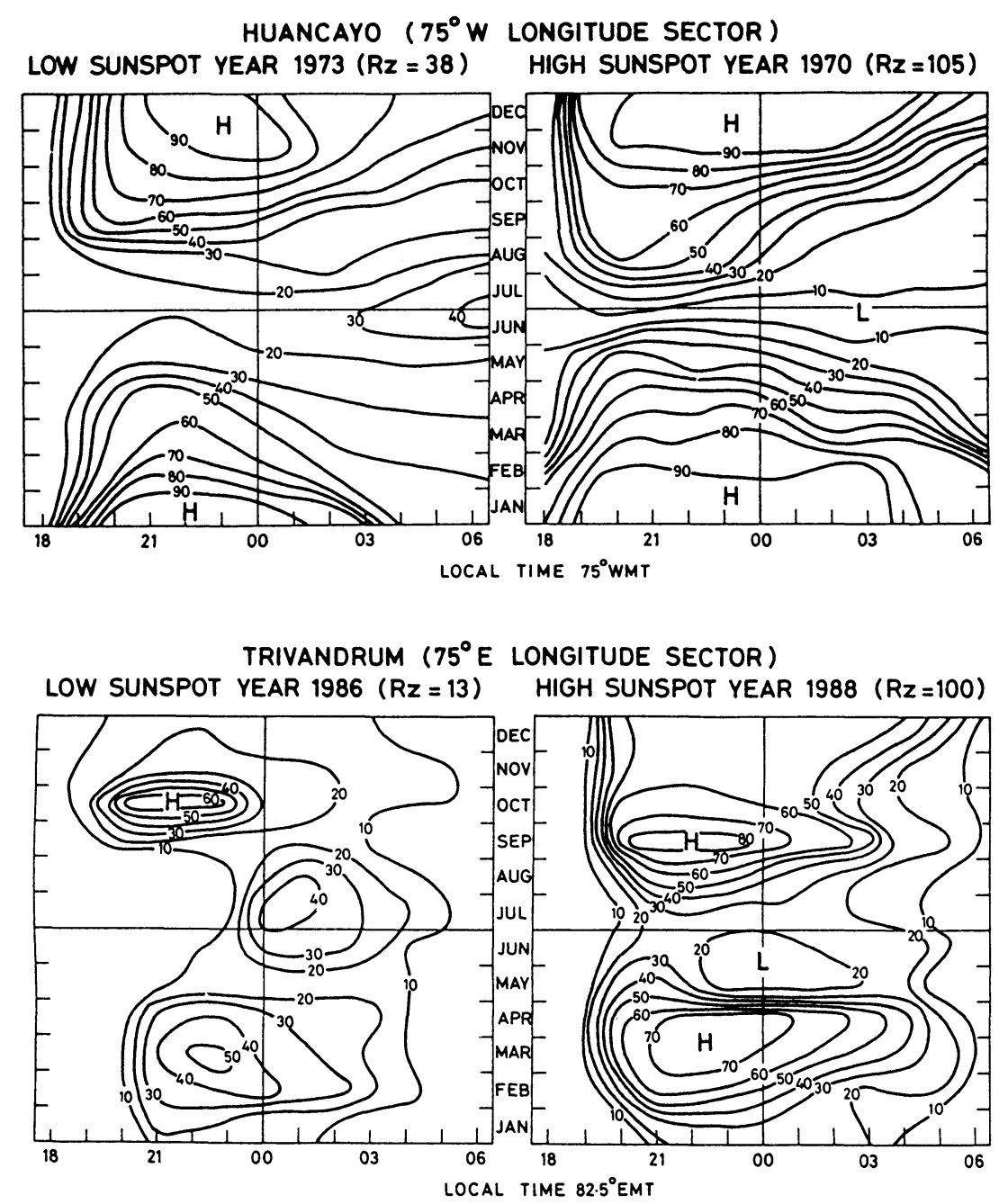

Fig. 3. Contours of percentage occurrence of scintillations at Trivandrum and Huancayo on the grid of local time and months for years of low and high sunspots.

scintillations at Trivandrum increased significantly with the increase of solar activity, whereas scintillations at Huancayo show comparatively less dependence on solar activity.

To study the effect of magnetic activity on the percentage occurrence of scintillations, five internationally quiet and five internationally disturbed days were selected from every month's data for the entire period of observations, and for every hour the averaged values were calculated separately for low and high sunspot years. These curves are shown in Fig. 5.

Regarding Trivandrum, a magnetic disturbance effect is not clear during the low sunspot years, when the average scintillations are very low. During high sunspot years, the scintillations are significantly reduced during geomagnetically disturbed 

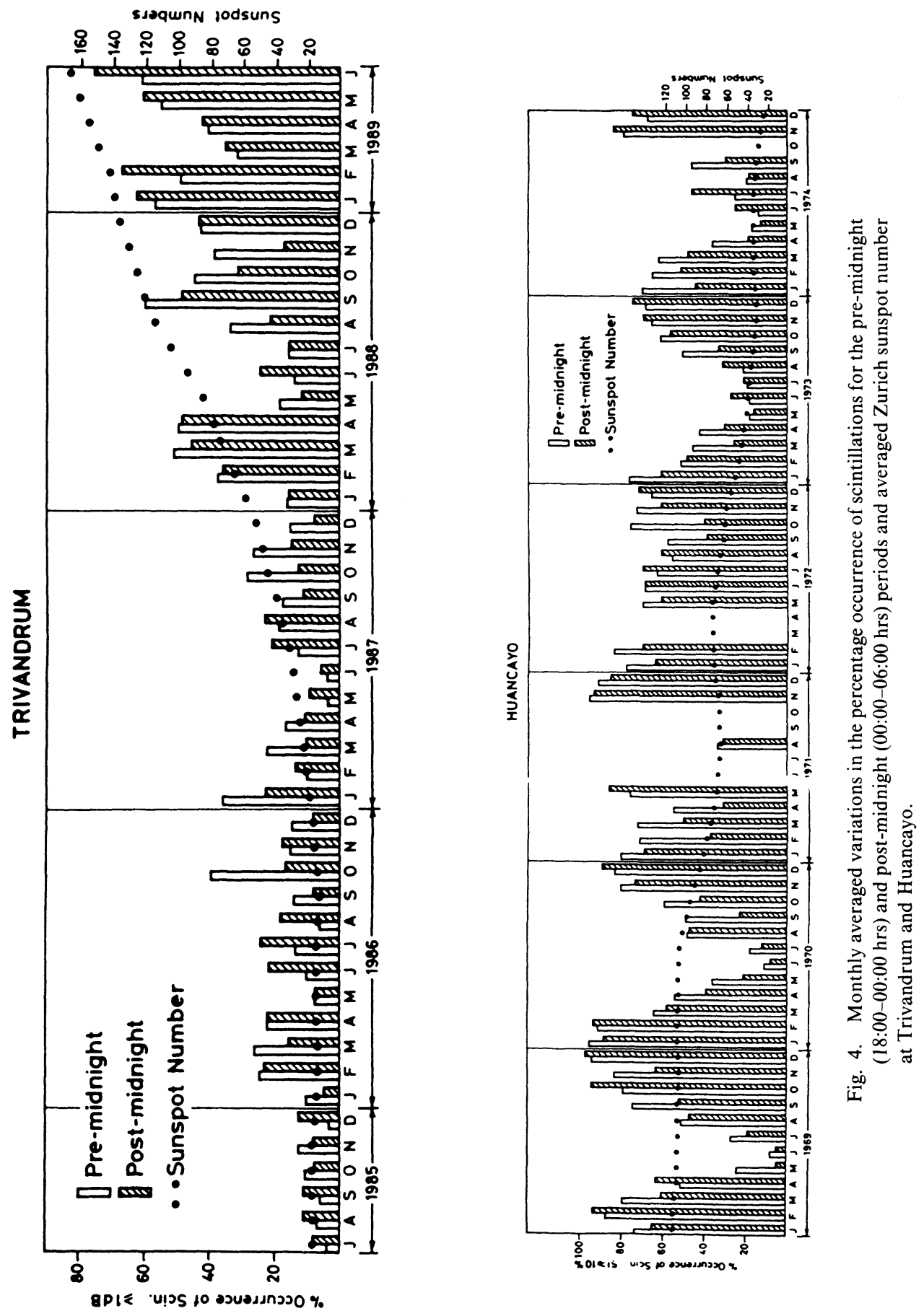


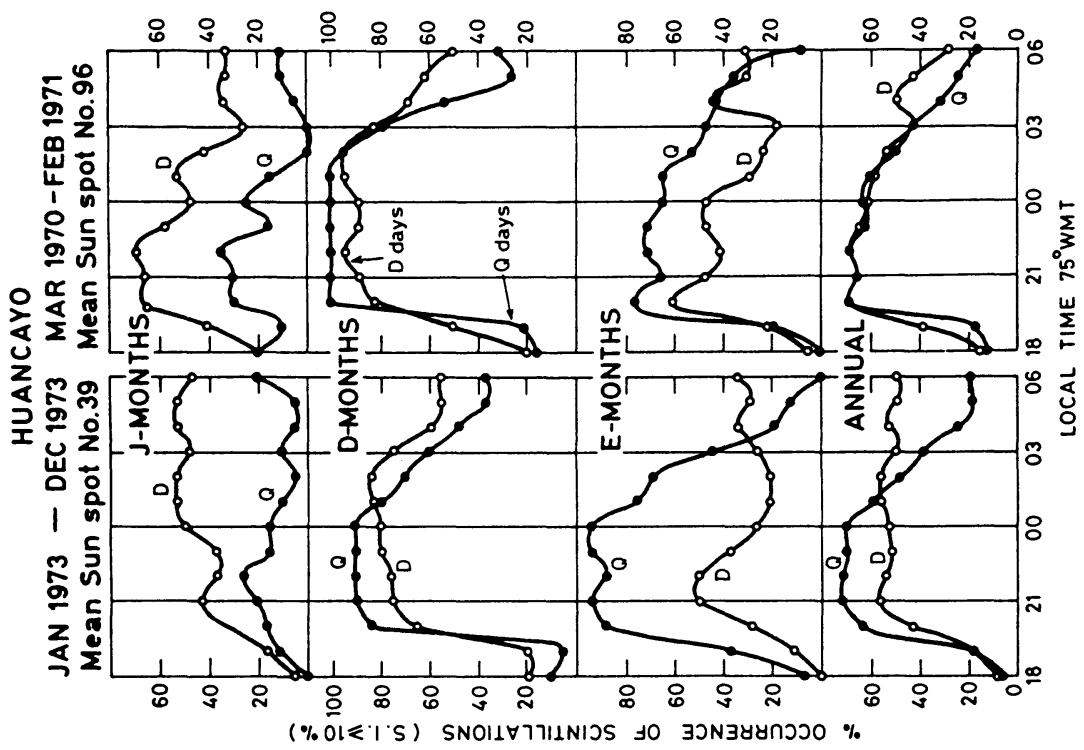

究
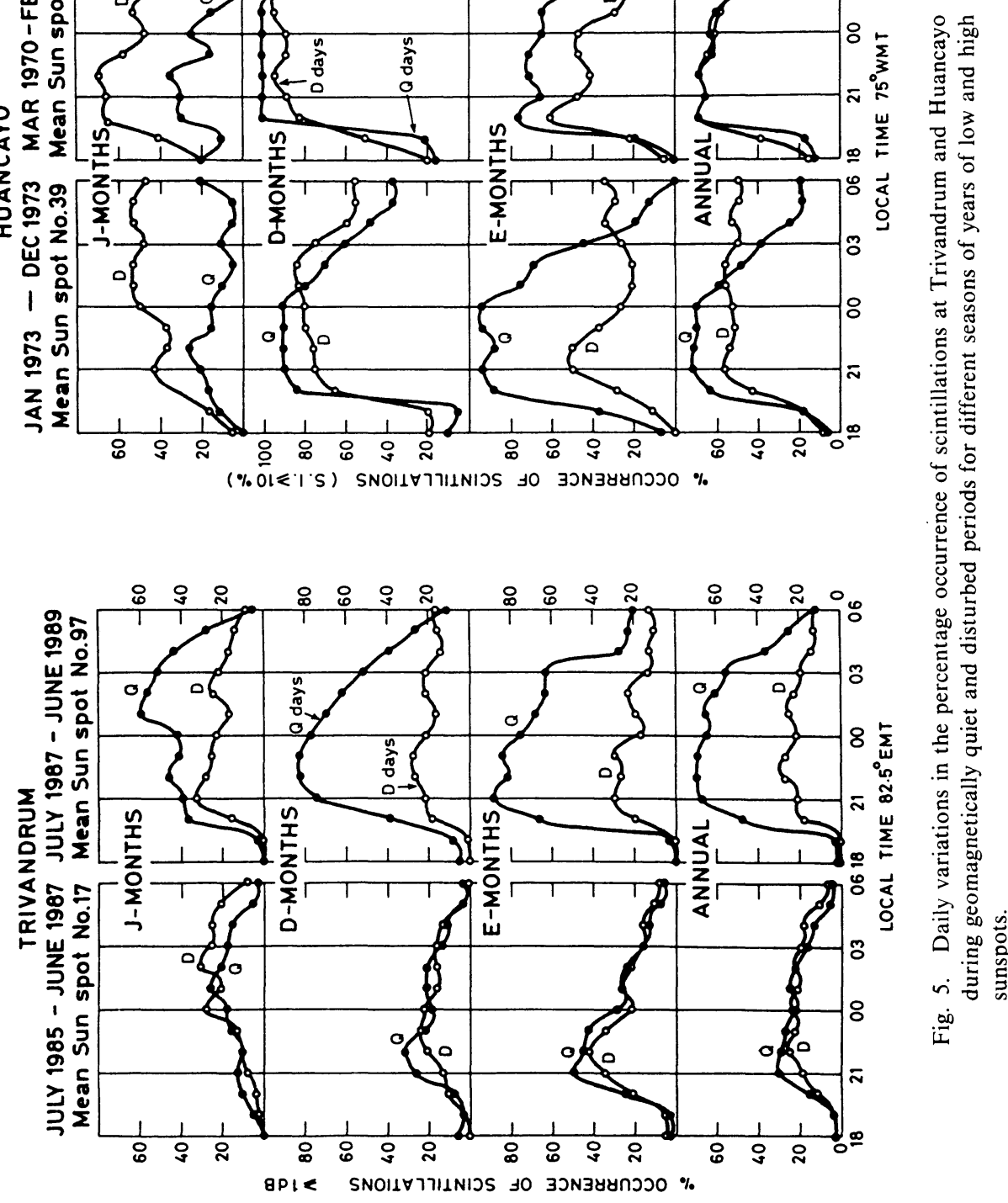
days.

At Huancayo, the scintillations are reduced on disturbed days during the Eand D-months but are increased during the J-months. Here again, the characteristics of scintillations are very different in the Indian and American zones.

\section{Discussion}

This paper presents, for the first time, long-term VHF radio wave scintillation measurements done at an equatorial station in Indian longitudes and compares them with those from the American zone. Before this, the only observations, though for a comparatively shorter period, done in India are those of KRISHNA MOORTHY et al. (1979), for Trivandrum $\left(0.95^{\circ} \mathrm{dip}\right)$ and those of RASTOGI et al. (1982) for Ootacamund. For analysis, in this paper we have considered scintillations having amplitude fluctuations (peak-to-peak) $\geq 1 \mathrm{~dB}$, whereas KRISHNA MOORTHY et al. (1979) considered amplitude scintillations $\geq 0.25 \mathrm{~dB}$ above the mean level for the analysis; hence, these are not directly comparable with our results. However, KRISHNA MOORTHY et al. (1979) have shown that the percentage occurrence of scintillation is maximum at $40 \mathrm{MHz}$ and least at $360 \mathrm{MHz}$. Also, the occurrence probability is maximum in December, February and June for $40 \mathrm{MHz}$, whereas for $140 \mathrm{MHz}$ and $360 \mathrm{MHz}$ the June peak is absent. RASTOGI (1982b) has reported the solar cycle effects on radio wave scintillations based on Huancayo data for $\mathrm{SI} \geq 20 \%$. However, for comparison we have used the data for $\mathrm{SI} \geq 10 \%$ which corresponds to peak-to-peak fluctuation $\geq 1 \mathrm{~dB}$.

RASTOGI (1980) has shown that the post-sunset generation of range spread- $F$ in the American zone is positively correlated with sunspot numbers, and has a maximum occurrence probability for high sunspot years. It has also been shown that the range of spread- $F$ has a broader response, as far as nocturnal variations of the occurrence probability are concerned, during sunspot minimum periods, owing to the comparatively larger occurrence of range spread in the post-midnight period. In high sunspot periods, there seem to be rapid decreases in the occurrence probability after midnight. So, on the average, an inverse correlation between range spread and solar activity is observed. For frequency spread, the occurrence probability is maximum around June and July. There is no marked difference in the occurrence probability of frequency spread with solar activity (i.e., the frequency spread is independent of solar activity). For Kodaikanal station in the Indian zone (dip $3.5^{\circ} \mathrm{N}$ ), SASTRI et al. (1979) have shown that range spread and frequency spread are positively correlated with the solar cycle phase. During high sunspot years, the range spread is maximum in the pre-midnight period and the frequency spread is prominent in the post-midnight period. During low sunspot periods, range spread is dominant throughout the nighttime. During periods of moderate solar activity, range spread is again dominant throughout the nighttime, except during the presunrise hours. Thus, spread- $F$ characteristics are different in the Indian and American zones. HUANG (1970) has reported a positive correlation between range spread and sunspot number and a negative correlation between frequency spread and sunspots for the mid-latitude/low latitude station, Taipei $\left(\operatorname{dip} 19^{\circ} \mathrm{N}\right)$.

From the amplitude scintillations at 40,140 and $360 \mathrm{MHz}$ recorded at Ootacamund $\left(\operatorname{dip} 4^{\circ} \mathrm{N}\right)$ and the ionograms at a nearby station, Kodaikanal (dip 
$3.5^{\circ} \mathrm{N}$ ), CHANDRA et al. (1979) have shown that range spread is associated with strong radio wave scintillations observed on all frequencies, whereas the frequency spread is associated with weak scintillations observed at $40 \mathrm{MHz}$ only. KRISHNA MOORTHY et al. (1979) have shown the correlation between the range spread and VHF scintillations at 40,140 and $360 \mathrm{MHz}$, for the equatorial station Trivandrum (dip $0.9^{\circ} \mathrm{N}$ ). RASTOGI $(1982 \mathrm{a}$, b) has shown that the equatorial range spread at Huancayo, having multiple scattering layers of intense ionization, is associated with very fast and saturated scintillations. Similar results obtained from simultaneous measurements of VHF scintillations and range spread- $F$ have been reported by HuANG (1970) for Taipei, and by HAJKOWICZ (1977) for the station at Brisbane, Australia.

From the present results of radio wave scintillations reported here, for the equatorial station in Indian longitudes, the percentage occurrence of scintillations is maximum in equinoctial months during the years of both low and high sunspot numbers. However, the maximum peak is shifted to 22:00 hrs during the years of high sunspot number, compared to $21: 00 \mathrm{hrs}$ in the years of low sunspots. In $\mathrm{J}$-months, the peak of maximum scintillation occurrence, which was observed in the post-midnight hours during the years of low sunspot numbers shifted to the premidnight hours during the years of high sunspot numbers. This is very similar to the characteristics of spread- $F$ for summer months, as reported by SASTRI et al. (1979) and CHANDRA and RASTOGI (1972). In American longitudes, the maximum occurrence of scintillations was in D-months in years of both low and high solar activity, with the peak maximum around 23:00 hrs.

From our studies of variations in the occurrence probability during geomagnetic quiet and disturbed conditions in Indian longitudes, on an average, scintillation activity is reduced in the high sunspot years in all seasons, while no clear effect was seen during the years of low sunspot numbers. In American longitudes, the occurrence probability of scintillations on quiet days is greater than on disturbed days in the pre-midnight hours; the reverse holds true for the post-midnight period for E- and D-months. In the J-months, scintillations are found to occur more frequently on disturbed days than on quiet days for any hour of the night.

DAS GUPTA et al. (1981) have described the characteristics of VHF scintillations at Calcutta, a station near the equatorial anomaly crest in the Indian zone. With increased solar activity, the occurrence of scintillations increased remarkably during the equinoxes and to a lesser extent during the December solstices, while the local summer occurrence showed little change. These features are similar to those observed at equatorial station Trivandrum, suggesting close association between the equatorial and tropical latitude scintillations.

\section{Conclusion}

The present results show conclusively that, similar to the occurrence of spread$F$ at the equator, the occurrence of VHF radio wave scintillations show significant longitudinal differences between the Indian and American sectors. Scintillations are most frequent during equinoxes in the Indian sector and during December solstices in the American sector. With a decrease of solar activity, the scintillation activity decreases much faster in the Indian sector than in the American sector. 
The VHF receiving set at Trivandrum has been operated by Mr. Unnikrishnan Nair; Thanks are due to him for an excellent set of observations. The research at the Indian Institute of Geomagnetism is supported by the Department of Science and Technology, Government of India.

\section{REFERENCES}

Aarons, J., Global morphology of ionospheric scintillations, Proc. IEEE, 70, 360-378, 1982.

Basu, Su. and S. Basu, Equatorial scintillations: Progress since ISEA-6, J. Atmos. Terr. Phys., 47, 753-768, 1985.

Basu, Sa., Su. Basu, J. Aarons, J. P. McClure, and M. D. Cousins, On the coexistence of kilometer and meter scale irregularities in the nighttime equatorial $F$ region, J. Geophys. Res., 83, 4219-4226, 1978.

Basu, Sa., Su. Basu, J. Labelle, E. Kudeki, B. G. Fejer, M. C. Kelley, H. E. Whitney, and A. BushBY, Gigahertz scintillations and spread receiver drift measurements during Project Condor equatorial $F$ region rocket campaign in Peru, J. Geophys. Res., 91, 5526-5538, 1986.

Chandra, H. and R. G. Rastogi, Equatorial spread-F over a solar cycle, Ann. Geophys., 28, 709-716, 1972.

Chandra, H., Vats, G. Sethia, M. R. Deshpande, R. G. Rastogi, J. H. Sastri, and B. S. Murthy, Ionosphere scintillations associated with features of equatorial ionosphere, Ann. Geophys., 35, $145-151,1979$.

Das Gupta, A., A. Maitra, and Sa. Basu, Occurrence of nighttime VHF scintillations near the Equatorial crest in the Indian sector, Radio Sci., 16, 1455-1458, 1981.

Hajkowicz, L. A., Multisatellite scintillations, spread- $F$ and sporadic E over Brisbane-1, J. Atmos. Terr. Phys., 39, 359-365, 1977.

HuAng, C. M., $F$ region irregularities that cause scintillations and spread- $F$ echoes at low latitude, $J$. Geophys. Res., 75, 4833-4841, 1970.

Kelley, M. C., J. Labelle, E. Kudeki, B. G. Fejer, Sa. Basu, Su. Basu, K. D. Baker, C. Hanuise, P. Argo, R. F. Woodman, W. E. Swartz, D. T. Farley, and J. W. Meriwether, Jr., The Condor equatorial spread- $F$ campaign: Overview and results of the large-scale measurements, J. Geophys. Res., 91, 5487-5503, 1986.

Krishna Moorthy, K., C. R. Reddi, and B. V. K. Murthy, Nighttime ionospheric scintillations at the magnetic equator, J. Atmos. Terr. Phys., 41, 123-134, 1979.

Rastogi, R. G., Seasonal and solar cycle variations of equatorial spread-F in American zone, J. Atmos. Terr. Phys., 42, 593-597, 1980.

Rastogı, R. G., Nighttime ionospheric scintillations and $E \& F$ region irregularities at the magnetic equator, Ind. J. Rad. \& Spa. Phys., 11, 1-14, 1982a.

Rastogı, R. G., Solar cycle effect on radio wave scintillations at Huancayo, Ind. J. Rad. \& Spa. Phys., 11, 215-221, 1982b.

Rastogi, R. G., H. Chandra, and M. R. Deshpande, Equatorial radio scintillations of ATS-6 radio beacons: Phase II Ootacamund 1975-76, Ind. J. Rad. \& Spa. Phys., 11, 240-246, 1982.

Sastri, J. H., K. Sasidharan, V. Subramanayam, and S. Rao, Range and frequency spread- $F$ at Kodaikanal, Ann. Geophys., 35, 153-158, 1979.

Szuszczewicz, E. P., P. Rodriquez, M. Singh, and S. Mango, Ionospheric irregularities and their potential impact on synthetic aperture radars, Rad. Sci., 18, 765-774, 1983.

TAUR, R. R., Ionospheric scintillations at 4 and $6 \mathrm{GHz}$, COMSAT Tech. Rev., 3, 145-163, 1973.

Whitney, H. E., J. AARons, and C. Malik, A proposed index for measuring ionospheric scintillations, Planet. Space Sci., 17, 1069-1073, 1969. 